\title{
Making Well-being an Experiential Possibility: The Role of Sport
}

\section{Abstract}

Whilst the relationship between active participation in sport and well-being has been widely acknowledged, less attention has been paid to actually understanding this relationship from the perspective of the individual. Our paper draws upon phenomenological philosophy and the existential life world view of well-being as proposed by Todres and Galvin (2010) and Galvin and Todres (2011), in order to explore how the experience of sport can help facilitate possibilities for multiple kinds and levels of well-being. In doing so, our paper highlights the multiplicity of the dimensions of well-being, and offers examples of the different paths to well-being provided by sport thus providing ways of describing wellbeing experiences within a sports context that are more complex than those offered by more traditional approaches to study in this area. Within this conceptual analysis we adopt a humanistic approach that considers the multiple ways wellbeing can be experienced through sport as a sense of dwelling, mobility, or dwelling-mobility within the life world dimensions of temporarily, spatiality, mood, embodiment, inter-subjectivity, and identity.

\section{Key words}

Sport, Well-being, Phenomenology, Life-world, Dwelling-mobility 


\section{Introduction}

The aim of this paper is to draw upon the existential life world view of well-being (Todres,Galvin, \& Dahlberg, 2007; Dahlberg, Todres, \& Galvin,. 2009; Todres \& Galvin, 2010; Galvin \& Todres, 2011) and phenomenological philosophy (Heidegger, 1959; 1962; 1966; 1975; Merleau-Ponty, 1968; 1987; 1995) in order to explore how the experience of sport can help facilitate possibilities for multiple kinds and levels of well-being. In doing so we offer a human-centred approach to understanding the relationship between well-being and sport, an approach that emphasises a sense of agency and situated freedom.

\section{The Relationship between Sport and Well-being}

Over the past decade both academics and policy makers have suggested that participation in sporting activities can have both positive and negative effects on an individual's physical and mental well-being (Coakley 2007; Gould \& Carson, 2008; Department of Health, 2011). Sport clearly has the potential to have a negative impact upon well-being, for example through subjecting participants to somatic, social, and mental (Markser, 2011) or physical stress (Omalu, Hamilton, Kamboh, DeKosky and Bailes 2010). Tthe supposition that sport offers the potential for enhanced well-being has been reflected within recent health policy within the United Kingdom. Thus increasing sport participation is integrated through Public Service Agreements (PSAs) designed to "promote better health and well-being for all” demonstrating the acceptance of a positive relationship between sport and well-being (Bullough, 2012, p.43). Furthermore, the NHS Sport and Health Programme cites the advantages of sport in improving physical and mental health as the justification for the Department of Health’s continued engagement (National Health Service Confederation, 2013). Further evidence of this association is also apparent on a wider scale with the European Sport Charter defining sport as “all forms of physical activity which, through casual 
participation, aim at expressing or improving physical fitness and mental well-being, forming social relationships or obtaining results in competition at all levels" (Council of Europe, 1993 p.1).

The positive relationship between sport and well-being seems to be widely accepted. The idea of well-being, however, remains a complex and ambiguous term which lacks clear conceptualisation (Ryan \& Deci, 2001; McMahan \& Estes, 2011). While there remains no universally accepted definition of well-being, attempts at conceptualisation agree that it is both a positive and holistic notion that relates to optimal functioning and experience (Ryan \& Deci, 2001). Although the precise nature of optimal functioning remains ambiguous, many conceptualisations honour the concepts of hedonism and eudemonism as essential components of wellbeing (Mcmanhon \& Estes 2011). Whilst hedonic approaches view wellbeing as pleasure or happiness (Ryan \& Deci, 2001) alternative conceptions draw upon Aristotle's theory of Eudemonia, seeing wellbeing as doing or living well. Whilst many academics support either the hedonic or eudemonic notions of wellbeing, Mcmanhon and Estes (2011) show that both dimensions are associated with well-being, although more robust associations are indicated through the eudemonic dimension. Despite the emergence of this eminent research, there is an on-going need to formally conceptualise this term in order for it to become a more meaningful focus for future research.

In addition to the existing research narrative working towards providing a clear conceptualisation of well-being, academics have also endeavoured to explore its relationship with sport. The majority of work that has been undertaken to date has explored the relationships between sport and well-being from one of three disciplines. Economic perspectives have tended to explore relationships between participation and measures of well-being, generally adopting relatively large-scale secondary data sets conceptualising well-being in terms of happiness or life satisfaction (Dolan, Peasgood, \& White, 2008). Psychological studies have focused on the relationships between participation and particular aspects of well-being, such as self-esteem, or through the use of theoretical frameworks 
such as self-determination theory to explain such relationships (e.g. Lloyd \& Little, 2010). Finally, physiological studies have explored the neurophysiological mechanisms of subjective well-being achieved through exercise, such as the effects of exercise on the release of endorphins (e.g. Hoffman, 1997). Within each of these disciplines, research in the field of well-being has, for the most part, adopted a normative perspective, using objective measures and generalised standards (Lundqvist, 2011). One example of such normative objective measures of well-being is that provided by the United Kingdom’s Office of National Statistics (Self \& Randall, 2013). They propose that the factors affecting individual well-being include relationships, health, what individuals do (including taking part in sport), where they live, personal finance, education and skills alongside multiple contextual domains. This emphasis upon objective measurement is reinforced by the systematic review of Eime, Young, Harvey, Charity, and Payne (in press), which, although focusing on the concepts of social and psychological health of adolescents, rather than well-being per se, identified only two qualitative studies that met their criteria for inclusion, suggesting a clear positivist bias.

A further limitation with many existing studies is that of their chosen research design. Within the literature as a whole, many studies are cross-sectional and tend to identify correlational, rather than causal relationships (Eime et al., in press), focusing on single measures of well-being, with two associated limitations. The first is in terms of assuming that the association between participation and well-being can be reduced to simple relationships. As Biddle and Mutrie (2008) suggest, “possible explanations for why physical activity might influence mental health and well-being are likely to work in a synergistic way...perhaps it is this gestalt which provides the effect rather than one mechanism explaining one outcome” ( p.197). The second is the operationalisation of wellbeing in a number of contrasting ways. The validity of any quantitative research depends upon the appropriate measure of the relevant concept; however within much well-being research this is questionable. Lehnert, Sudeck and Conzelmann (2012, p.88) note, for example, that well-being “is 
frequently "whatever an investigator has identified as being the psychological dependent measure in his/her investigation.” Many studies fail to define, or often even discuss the concept of well-being in any depth. Ntoumanis, Taylor and Thøgersen-Ntoumanis (2012), for example, appear to view well-being as simply a measure of physical vitality. Others take a more multidimensional view, such as Verkooijen, van Hove and Dik (2012) who conceptualise well-being simply as 'Quality of Life’ using four separate domains: physical health, environment, social relationships, and psychosocial health. For economists, well-being is often conceptualised as 'happiness' (Kavetsos \& Szymanski, 2008). The problems with such varied theorisations are highlighted by Rejeski and Mihalko (2001, p. 24), who note that if well-being “is intended to be a psychological construct yet is used as an umbrella term for multiple outcomes, then there is no hope of developing theory or of ever understanding what causes variability or change in quality of life”.

Whilst such conceptualisations provide a systematic and pragmatic model for measuring well-being and developing associated policy, such an objective structural approach neglects the personally constructed meanings that may be attributed to well-being. Consequently, much of the research that discusses this concept fails to be truly meaningful for individuals, and often fails to take a humancentred approach to understand how well-being is experienced. Although such human-centred approaches emphasise the subjective nature of well-being, they emphasise a need to understand the domains in which well-being is experienced in order to adequately inform future policy and practice. Thus, it seems clear that there is a need for alternative qualitative approaches to the study of the relationship between sport and well-being that go beyond that of simply identifying and measuring relationships between varied concepts, and focus more upon the lived experiences of well-being. One such perspective is that of the life world approach to the study of sport and wellbeing.

\section{A life world approach to sport}


Phenomenological approaches to the study of sport are not new, and examples of its use and its potential are outlined by Allen-Collinson (2009). Despite this, there is currently a deficit of humanistic academic literature that explores how sport may provide opportunities for well-being to be experienced. In order to explore such experiences of well-being for individuals, it is possible to draw upon phenomenological philosophy that views the individual as having a sense of agency and existential freedom as opposed to being purely determined by existing objective structures. Such an approach will contribute a level of depth to the existing research exploring wellbeing within a sport context by focusing on subjective human experiences of wellbeing provided by sport as opposed to investigating relationships between more objective variables.

Heidegger (1962) uses the term situated freedom to explain the view of the individual as having both structure and agency. He states that our freedom is situated when an individual still engages with the structure of the world in terms of the imposed limitations of being human, whilst also having distinct possibilities for agency in being an individual. Such an approach provides an emphasis on human-centeredness in order to fully understand the way in which sport and well-being may be connected, and how sport could provide opportunities for well-being. Furthermore, by drawing upon such phenomenological philosophy, sport researchers are able to avoid the dualistic Cartesian tradition that views mind and body as oppositional and isolated, and provide a more embodied description of how well-being becomes an experiential possibility through sport.

A key foundation for this approach is that of the idea of the life world. The life world comprises everyday life and situations as perceived by us, and our subjective experiences of our self, body and relationships, as opposed to the objective meanings or measurements often attached to those experiences. Dale (1996) argues that we should view an athlete as being "indissolubly linked to his or her world whether it be in practice or competition. The two (athlete and world) do not exist apart from each other and each individual and his or her world are said to co-constitute one another, 
which is another way of saying you cannot really talk about an athlete without talking of his or her world” (p.309). This world consists not just of our embodied experiences, such as sight, touch or physical activity, but also our value judgments, such as aesthetic appreciation, and our understanding of the existence of other subjective beings within that life world. As Todres, Galvin and Dahlberg (2007, p55) suggest:

"it is a world that appears meaningfully to consciousness in its qualitative, flowing givenness; not an objective world “out there”, but a humanly relational world, full of meanings. The primary nature of this relational reality means that there is no objective world in itself, nor an inner, subjective world in itself; there is only a world-to-consciousness”.

Although the life world should be viewed holistically, it is useful to examine the intertwined constituents of which it is comprised. Thus, by exploring the ideas of temporarily, spatiality, embodiment, inter-subjectivity, and identity, the subtleties and nuances of an individual's life world can be described and understood. The contrasts between this approach and the dominant approaches within the existing sport/well-being literature are clear. As previously stated, the prevalent approaches to exploring the relationship between sport and wellbeing generally rely on more quantitative data collection methods such as scales and questionnaires. Whilst such measures may incur a level of subjectivity in terms of how they are interpreted by participants, in comparison to the life world approach, these approaches to data collection are largely objective. Accordingly, rather than focus on more objective measures of the effect of sport on well-being, our emphasis is upon how the individual experiences well-being through sport.

\section{Movement, Peace and Vitality}


Dahlberg et al. (2009) extend the work of Todres et al (2007), suggesting that "the experience of well-being means an existence characterized by vitality, which encompasses the possibilities of movement and the possibilities of peace” (p.267). In other words, the seemingly dualistic notions of movement and peace are both characteristics of the wellbeing experience. Furthermore, a sense of movement and peace can be experienced through each of the life-world dimensions in wellbeing experiences. It is to the specifics of these qualities of movement and peace that we now turn. To describe the movement quality of vitality which they term "existential mobility” (p. 267) Dahlberg et al. (2009) draw heavily on the work of Heidegger (1962) and Merleau-Ponty (1968; 1987; 1995) to describe it as a sense of being able to move into possibilities of engagement with other people, spaces, moods, or times. In their paper on the promotion of vitality in health and physical education, Smith and Lloyd (2006) provide an exemplary overview of vitality centered on movement including rushes, bursts, surges, swells, risings, undulations, waves, and flows. As opposed to accepting normative measures of vitality, they provided additional depth to the measures "from the perspective of the living breathing, moving person who seeks wellness” (p.263). Therefore, by drawing upon these approaches, and conceptualising well-being as involving a felt sense of vitality, it is necessary to reflect on an individual's possibilities for movement, which may be experienced in numerous different physical and metaphorical ways such as bursts of speed or activity, or the sense of actualisation or moving forward. In other words, movement can be seen as a vital component of vitality and wellbeing.

In addition to describing the movement quality of vitality, Dahlberg et al. (2009) confer the notion of peace as an additional complementary quality. In contrast to the dynamic quality of movement, essentially peace is a familiar and comfortable stillness, a “...coming to terms with, and even ' ...a welcoming' of the present moment” (Dahlberg et al., 2009 p.268). According to Dahlberg et al. (2009) despite the clear contrast between movement and peace, both provide possibilities for experiences characterized by vitality (or wellbeing experiences). Therefore both dynamic 
movement and familiar peacefulness provide opportunities for wellbeing. In order to further explore peace as a quality within vitality the authors draw upon Heidegger's notion of 'letting-beness” (1975), which they define as a sense of a reconciliation of what has been and life's possibilities. Heidegger (1959) defines "letting-be-ness" as releasement toward things in the sense of an acceptance of what may come. Therefore, peace can be defined as a sense of feeling at home with one's self or situation.

Whilst initially movement and peace may seem oppositional and uncomplimentary Dahlberg et al. (2009) describe vitality as the intertwining of the two. The nature of the relationship between these two components of vitality can be exemplified further by delving deeper into Heidegger's theory of releasement. As previously stated Heidegger (1975) describes the letting-be-ness that is allied to peace as releasement toward things. Specifically he notes that: "Releasement toward things and openness to the mystery belong together. They grant us the possibility of dwelling in the world in a totally different way” (p. 55). In this sense Heidegger elucidates that by letting life’s past, present and future 'be', one can gain a sense of releasement that will provide new possibilities for the way that one dwells in the world. In this statement Heidegger illuminates how a sense of openness can provide opportunities for movement. Todres and Galvin (2010) expand on the earlier work by Dahlberg et al. (2009) to explore the interaction between movement and peace by drawing upon Heidegger’s theory of “homecoming”. In his earlier work, Heidegger (1962) describes being-athome (Zuhause-sein) as a sense of “...obviousness, into the average everydayness” (p.189) of being in the world, which brings a sense of tranquil reassurance. In other words, at-homeness refers to being in the world in a familiar way that provides one with a sense of comfort. Todres and Galvin (2010) draw upon Heidegger (1962) to explain that this sense of at-homeness may be taken for granted if experienced in isolation from alternative ways of being in the world, characterized by human beings taking "excessive refuge” (p.2). Such an isolated experience can be viewed as inauthentic (Todres and Galvin, 2010) in the sense that it is not experienced in the light of alternative 
ways of being (namely homeless-ness). In apparent contrast to at-homeness,, Heidegger explains that anxiety “...fetches Dasein (being there) back out of its entangled absorption with the "world” (p.189), which forces individuals into the existential mode of not-being-at-home (Un-zuhause). Similar to the aforementioned in-authentic notions of at-homeness, Heidegger (1962) explains that homelessness also may be an isolated experience for humans if experienced without at-homeness. Todres and Galvin (2010) draw upon Heidegger's later works that discuss the broader concept of homecoming as a more authentic experience for individuals as opposed to an isolated sense of being-at-home or not-being-at-home. They explain that:

Facing this “not being at home”, although an anxiety-provoking experience, can open up a path of movement; and this can provide an energising potential that can itself be felt as wellbeing (p.3).

Therefore the anxiety felt within the experience of homelessness can be an important enabler to the motivation to seek authentic homecoming, referred to by Todres and Galvin (2010) as “existential dwelling”. Taking their discussion further, one may also propose that the peace felt within the experience of homecoming may provide the confidence required to take risks in seeking authentic movement or "existential mobility", that together create a sense of vitality. Thus authentic athomeness or homelessness is experienced in the light of alternative ways of being in the world.

Todres and Galvin (2010) also draw upon Heidegger's notion of Gegnet in order to explain the interplay between existential dwelling and mobility. Heidegger defined Gegnet as "an abiding expanse which, gathering all, opens itself, so that in it openness is halted and held, letting everything merge in its own resting” (Heidegger 1966 p. 66). This concept provides additional illumination to the relationship between dwelling and mobility by describing an environment which offers a sense of acceptance, comfort and rootedness which can also offer opportunities for 
movement and adventure. In order to further explain the concept of Gegnet one can turn to autobiographical accounts of sporting experience to explore how peace and acceptance can be essential components of positive lived experience. In his auto-ethnographical account of training for and taking part in an Ironman Triathlon, McCarville (2007) attempts to explore why he was taking part in a sport “...that seemed so daunting” (p.159). Although McCarville (2007) experiences a sense of risk, anxiety and challenge (movement) in taking part in such an activity, he uses familiarity and comfort (peace) in order to ensure that the experience is positive.

"The Ironman swim would take me just over an hour, and I had practiced to ensure that it would be a positive experience. After all, it would start my big day. I think of the group workouts in which I had participated on a lake near home. Jeff, a professional triathlete, his wife Annika (my training partner), and I are swimming together in the lake. It is flat and calm as I watch the homes and cottages glide past. I concentrate on making my stroke as efficient as possible.” (p.165)

The above quotation demonstrates that sporting experiences offer the opportunities for movement and adventure such as competition, which are grounded in peace, through the development of known movements or embodied knowledge and training. Furthermore, when describing the cycling leg of the Ironman, the author describes how vitality is experienced as peace grounded in movement:

A moment ago my back was sore, my legs felt like lead, and my saddle seemed like an instrument of torture. Now I'm feeling the sensation of speed and control as I manoeuvre through the crowds (p. 167). 
This experience offers a sense of authentic peace and control which is grounded in the experience of movement. This also relates to Heidegger's notion of authenticity in homecoming which acknowledges that anxiety can be an important enabler to the motivation to seek authentic sense of peace.

In this paper, McCarville (2007) also draws upon the earlier work of Mitchell (1983) who explored the goals and motivations of high-altitude climbers. A climber in Mitchell's research had explained that his ultimate goal was to seek uncertain or anxiety-provoking situations (movement) and through the application of personal skill and preparation (peace), render themselves as safe, and the experience as positive. Thus the climber experiences a sense of authentic movement in the light of peace, demonstrating the interplay between the two components of vitality experiences. Through these autobiographical sporting examples we are able to explore the concept of Gegnet in a more practical sense. This notion of Gegnet is used to inform the existential theory of well-being introduced by Todres and Galvin (2010) which demonstrates how dwelling, mobility, and dwellingmobility can be experienced within the various life world dimensions.

\section{Dwelling-Mobility}

We present a conceptual framework in the form of a dwelling mobility lattice (see Table 1) to demonstrate how experiences of dwelling, mobility, and interlinked dwelling-mobility can be experienced, in order to facilitate multiple kinds or levels of well-being (Galvin \& Todres, 2011).

*** TABLE ONE ABOUT HERE***

The framework presented in table 1 demonstrates how dwelling, mobility and dwelling-mobility may be felt within each of the life world dimensions identified within phenomenological philosophy. Using the typology, Galvin and Todres (2011) highlight that there are kinds of well- 
being possibilities where either dwelling or mobility may be explicitly emphasised. For example, within the spatial domain the well-being possibilities associated with a sense of at-homeness emphasise the dwelling aspects of vitality. Conversely, well-being possibilities associated with the sense of adventurous horizons emphasise the mobility characteristic. Whilst kinds of well-being possibilities exist that emphasise an individual feature of vitality, the authors also explain that there are also possibilities for deeper forms of well-being that involve the integration of both dwelling and mobility where these characteristics are intertwined.

\section{Spatiality}

Todres et al (2007) define spatiality as existence in relation to other objects, in terms of distance or closeness. Thus Spatiality refers to the environment within which we live, and how we experience that environment. This environment can either be facilitative or limit our experiences and opportunities. Spatial Dwelling refers to a sense of “at homeness", where well-being is experienced through the sense that one is in an environment of familiarity, routine and comfortableness. Sport can create such regularity, for example through regular timetabled training sessions or the use of a 'home' venue or stadia in creating a sense of regularity which has meaning to the participant. The runner, for example, can run a familiar route. 'Home' can also be in a metaphorical sense, for example, the consistent use of pre match rituals or superstitions, which can create a sense of stability for the individual, or the use of familiar music, which can elicit various positive emotional states before a performance (Bishop, Karageorghis, \& Loizou, 2007).

Sport also allows individual being tuned into the spatial possibilities of their environment. Spatial Mobility relates to what Galvin and Todres (2011) define as ‘adventurous horizons'. In the natural environment this can relate to viewing new opportunities or seeking new adventures. Sport provides a wealth of opportunity for such adventurous horizons, where travel to new locations, joining a new team or club, a change of sport, or even metaphorically, through reading books about sport can 
provide a sense of imagined adventure, opportunity and uncertainty. Thus, the individual might wish to travel to a new country, to take part in a new event, such as the runner who actively seeks out new events and new locations (Shipway \& Jones, 2007).

There is also the possibility of experiences that entwine both of these ideas. Thus Spatial DwellingMobility refers to the combination of both a sense of comfort and familiarity with the environment, but also the opportunities for new experiences. The beach, for example, becomes a running track whilst the sea becomes the swimming pool. Atkinson (2009) uses the example of Parkour, or free running, to explain how well-known urban landscapes can become a space for sporting engagement. He explains that free runners "see their own neighbourhoods and cityscapes as important physical environments to explore, experience, understand, and deconstruct through athletic movement” (p.173), familiar environments that, as Daskalaki , Stara and Imas (2008, p.51) suggest can “encourage chance, interaction, possibility, imagination, creativity and change”. Alternatively,new locations can be visited, whilst being with like-minded individuals. One of the particpants in the study of Shipway and Jones (2008) noted that:

I often find myself reflecting with running peers on past Marathons that we have completed over the past 15 years, often with a sense of nostalgia, pride and attachment to the event, the destination and the overall experience of participating in an unfamiliar running environment (p.68).

Through such intertwining of movement and peace, the opportunity is provided for the deepest sense of well-being.

Temporality 
Heidegger (1927) explains that the fundamental task of the interpretation of being includes "the elaboration of the temporality of being" (p.18) and explains that "being" is comprehensible only in relation to time. Todres et al (2007) explain that there are multiple ways that one can experience time, such as through the provision of possibilities or as a limiting pressure.

The concept of Temporal Dwelling emphasises 'present centredness', where an individual is totally tuned into the present moment. Although Heidegger's approach was more ontological in nature, this does provide clear parallels to the psychological concept of 'flow' (Csikszentmihalyi, 1990; 1997) and athletic mastery through skilful coping (Heidegger,1962). Thus Temporal Dwelling relates to the appreciation of the process, rather than the outcome of the sport. Hubert Dreyfus (1986) extended Heidegger's analysis to a phenomenology of mind states in sport, explaining how what he termed absorbed coping demonstrates the direct interaction of our bodies with the physical environment leaving little room for conscious attention, although, as Breivik (2007; 2013) suggests, such conscious attention will always be present, even if it involves a constant switching between conscious and unconscious mind states. Thus, the rock climber may complete a route with little conscious awareness at times. In contrast, however, the experience of time can also be more forward looking. Temporal Mobility emphasises the sense of positive future orientation, when an individual is tuned in towards future possibilities, this has clear parallels to achievement within a sporting environment, and the relationship between training and a sports event. The nature of sport allows such temporal mobility through its inextricable link to time (such as the presence of finite seasons for each sport, and set events, competitions and occasions). Thus, examples may include looking forward to a marathon.Without such Temporal Mobility, people may see themselves as stuck in a rut, or lacking any goals or ambitions.

The deepest forms of well-being associated with temporality, however, are those related to Temporal Dwelling-Mobility, which unify the present centeredness of sport participation with the 
future possibilities, where the participant is bound within the process, but with a focus on the future, for example whilst training for a marathon, such as the participant in the study of Shipway and Jones (2008) who noted that:

I turned into the type of person to avoid in the months leading up to the Marathon. I had only one topic of conversation and would waffle on about carb-loading, tapering and race day plans to anyone who had the misfortune to listen (p.69).

Ultimately Temporal Dwelling-Mobility relates to the well-being achieved through depth of the activity itself, but acknowledging the future, especially the openness and uncertainty of that future. Thus, it is entirely possible for the runner to experience absorbed coping within the present, but whilst training for an event in the future, both of which will be intertwined. It is not only for the individual to identify such possibilities, but also those future possibilities that are suggested by others, such as the coach, or parents (Bengoechea \& Strean, 2007).

\section{Embodiment}

This refers to the idea that we live within, and experience the world through our bodies, whether in a positive or a negative way. For Merleau-Ponty (1999) the human experience is intertwined with embodiment, and his views are particularly relevant here given his concern with embodied consciousness, referring to the existential renegotiation of the subject-object dichotomy which views bodies as mere objects or instruments. Instead, as Hockey and Allen Collinson (2007, p.117) suggest "the body is not so much an instrument nor an object, but rather the subject of perception, socially and indeed sub-culturally mediated though that perception may be. For us, we know the world through the body, just as that body produces the world for us”. 
Embodiment Dwelling refers to the literal experience of bodily comfort when one welcomes a sense of feeling 'at home'. Galvin and Todres (2011, p.10) suggest that this involves "reliable rhythms, as in the gentle rise and fall of the breath, or the relaxation of the body at rest”. McCarville (2007) talks about the reliable rhythms involved in the triathlon:

Swimming is perhaps the most technical part of a triathlon. A rhythm must be achieved. Bend your elbows and pull toward your feet, roll your body, snap your hips, and recover. Pull, roll, snap, recover. Pull, roll, snap, and so it goes. Once achieved, the rhythm has a certain magic (p. 165)

Such rhythms may be achieved post participation. The post-race cool down, for example, allows the individual to return to a state of comfort and familiarity, satiated by the involvement. This can be created by the individual the self, or facilitated by another, such as the physiotherapist performing post-event stretches for the runner. As well as a physical comfort, it can also relate to a sense of mental comfort or satiation, and a period of reflection and recovery during which the body returns to a state of 'normality'.

In contrast, Embodiment Mobility emphasises a sense of vitality that can be achieved through desired and valued bodily movement. Sport, by its very nature, provides an experience where individuals can experience their bodies in valued ways, achieving positive outcomes. Thus the basketball player may successfully complete a free throw, the gymnast may achieve a successfully choreographed routine, or the athlete with a disability may be able to restore a sense of vitality through the use of prosthetic limbs in Paralympic sport to maximise a dysfunctional limb and enhance movement. Again we can refer to McCarville (2007) who suggests that: 
I had run for a few hours but now I am walking quite a bit and trying not to limp. The muscle tear in my left leg is acting up. Pick up that leg, move it forward, ignore the pain, do it again. I round a sharp turn and see the finish line. The weight of the day's effort falls away and I feel as if I can run for hours. My legs are no longer sore. I am not tired. I pick up the pace and bound down that finishers' chute. I feel wonderful (p.168)

The intertwining of the sense of movement and peace, which can be experienced both concurrently and sequentially is described by the idea of Embodiment Dwelling-Mobility, which will allow for the deepest experience of well-being. Galvin and Todres (2011) refer to this as "bodily vibrancy" that involves potential and a readiness to look forward. Sport can provide possibilities for such grounded vibrancy as it combines both a sense of vitality and comfort, for example the climber who rests halfway to enjoy the view will experience this, as he or she experiences a sense of peace and rest, but at the same time experiencing a sense of vitality and excitement about returning to complete the activity.

\section{Mood}

Heidegger (1927) describes mood as a fundamental existential phenomenon. He explains that mood comes neither from "without" nor from "within" but is always part of "being- in-the world” (p137). For Heidegger, mood is always present, and, whether it is fear, anxiety or excitement, it is the fundamental way in which we are attuned to the world. Mood thus impacts on, and is impacted by one’s dimensions, whether spatial, temporal, inter subjective and embodied. The lived experience is thus "coloured by mood" (Todres et al., 2007, p57), whether that mood is one of peace, or one of excitement. Mood can be created by the sport itself, or the experience of sport can be coloured by the mood of the participant. 
Mood Dwelling relates to those moods that involve a sense of peacefulness or calm . Galvin and Todres explain that peacefulness can be experienced in multiple ways, such as an acceptance of, rather than fear, anger or anxiety about "what has been given". Sport can provide this sense of peacefulness in post-performance reflection, or the acceptance of one's performance regardless of outcome. This can relate to Coakley’s (2007) idea of 'pleasure and participation', where the focus is less upon the outcome, but more upon the pleasure of the process,. Breivik (2007, p.123) draws on Heidegger and Dreyfus to explain that even after years of engagement with activity such as sport "many people are not very good at it, but good enough in most cases to be satisfied", thus acknowledging that perfection, or even excellence in sport is not a requirement, simply a satisfaction with what has been achieved. In contrast, Mood Mobility emphasises the feeling of excitement or desire, with a sense of possibility. In sporting terms this could relate to the sense of uncertainty, nervousness or anxiety about the event itself. McCarville (2007) explains how mood can affect the experience of participation:

A moment ago my back was sore, my legs felt like lead, and my saddle seemed like an instrument of torture. Now I'm feeling the sensation of speed and control as I maneuver through the crowds. I can hear a roar of encouragement from those who line the streets. Flags, banners, and waving arms rush past in a blur. Take a hard right, lean, straighten up, and get up on the pedals to make up for speed lost in the turn. Feel the energy coming from the crowd. Concentrate, there's another turn coming. I can feel the mood change in the riders near me. They too are up on their pedals and pushing the pace.We are all attempting to show that we are worthy of the crowd's enthusiasm (p.167).

Galvin and Todres (2011) explain that Mood Dwelling-Mobility can be experienced as a sense of "multi-dimensional fullness" characterised by "giving oneself" without implication,. Thus the sense 
of risk brings an elevated mood, but without worry of failure. Sport provides this sense of multidimensional fullness, as within sport one is taking multiple risks and, by the very nature of sport, entering the unknown. For example, an individual taking the step to compete in their first road race, entering this willingly, and gives themselves to an experience, in spite of the risk of poor performance or injury. This unknown element in sport subsequently contributes to a sense of novelty and fullness, but without concern for the outcome or a resultant sense of fear or anxiety.

\section{Inter Subjectivity}

As social beings, we interact with others on a constant basis, living not as part of a social vacuum, but existing in relation to others. Inter subjectivity allows us to examine how we interact with others, and how we locate ourselves meaningfully within those interactions. The social nature of sport makes this a particularly germane aspect of the sport life world, with its emphases upon interaction, co-operation, and competition with others.

Inter-Subjective Dwelling stresses the idea of kinship and belonging, and effortless "being together". This can be experienced in a literal sense with an individual being with someone who they share a history with, such as in a team sport environment. However, Galvin and Todres (2011) explain that this can also be felt in a more metaphorical way "when we meet a "kindred spirit” (p.6) with whom we feel immediately compatible on various levels, such as personality, heritage, interest and so on. Within a sporting context this metaphorical sense of belonging can occur when one meets people with the same sporting experiences or interests, such as the experience of joining a new team. Within this experience one may feel a sense of immediate belonging, which may continue to grow as additional experiences are lived. This sense of kinship and belonging, and can also be achieved within individual sports as athletes engage with the sporting subculture. 
This contrasts with the idea of Inter-Subjective Mobility, which emphasises the role of "mysterious interpersonal attraction", Galvin and Todres (2011) describe this as an enigmatic sense when one wishes to find out more about another person, and develop a sense of bonding, or sense of gravitation towards another. Whilst there are clear implications towards fandom, there are also opportunities within participation that offer this sense of otherness, such as the concept of the sporting hero or role model, providing "the spark" associated with the mystery of otherness, and an opportunity to engage with this mystery, even though they might not engage with an individual in reality, it provides a leaning towards them. This can also be experienced through using the same equipment as a favourite player, or wearing replica kit whilst participating, which can also help this sense of engagement with the "other”. Shipway and Jones (2008) noted how a participant within the London Marathon realised that:

I was stood on the start line at Blackheath, only five metres from Stefano Baldini, the 2004 Olympic champion from Athens, and the current Marathon world record holder Paul Tergat from Kenya (p.67).

The intertwining of the two is described by the concept of Inter-Subjective Dwelling-Mobility, which refers to the "mutual complementarity" when a person feels the possibility developing new relationships with others, whilst maintaining existing relationships. This demonstrates the merging of the familiarity and the unknown, or sameness and difference. In his autobiographical paper exploring his experience of training for and taking part in an Ironman triathlon, McCarville (2007) describes inter subjective dwelling when he explains how he copes with the anxiety of the swim during competitions: 
I think of the group workouts in which I had participated on a lake near home. Jeff, a professional triathlete, his wife Annika (my training partner), and I are swimming together in the lake. It is flat and calm as I watch the homes and cottages glide past (p.165)

This recollection of his fellow triathletes provides him with a sense of dwelling, kinship and belonging. Inter-subjective dwelling is clearly an important feature of the positive experience for the author. However, he also describes his initial interaction with the competition athletes who he describes as a "splendid group” who all "look like Tarzan and Jane” (p. 164-165). Despite the anxiety provoked by seeing these competitors McCarville (2007) states that:

Suddenly, I’m feeling a certain kinship with all these passing Tarzans and Janes. I may not look as they do, nor do I feel as capable as they look, but I realize that we are all sharing in the same experience. We all have stories to tell and remarkable images to remember. I wish each of them well. We are all in this together. (p.165)

Shipway and Jones (2007) noted how such kinship emerged through elements such as sharing of stories, and the use of a common specialised language allowed a sense of kinship to be quickly developed among strangers. Although anxiety is produced through the movement of intersubjective mobility, this is grounded in the dwelling in common or shared experiences, thus exemplifying inter-subjective dwelling-mobility.

\section{Identity}

Identity focuses upon the ideas of not only the acceptance of being ("I am”) but of also the potential possibilities for the individual (“I can”). Identity Dwelling relates to the sense of being that comes with 'I am', and a feeling of acceptance and contentment with that state, rather than a having a feeling of 'a need to be'. Thus, for example 'I am a jogger', and contentment with that state of 
being, rather than a focus on future goals, such as feeling the need to achieve the identity of a marathon runner. Thus a sense of acceptance of one's own activity is present, without a felt need to advance. Identity Mobility refers to such possibilities, exploring the idea of "being able to", or the sense of “ I can” (Galvin \& Todres, 2011). This places emphasis upon one’s own personal sense of competence in being able to move towards a desired future, the achievement of realistic and appropriate goals, and a sense of accomplishment. In his auto-ethnographical account of the experience of training for and taking part in an Ironman competition, McCarville (2007) describes experiencing wellbeing as a sense of "I can":

One class in particular involved a difficult set of "hill climbs.” Although we were all gasping for air because of the physical effort, I noticed that the mood remained upbeat and everyone was having a great time. I could feel a virtual cocktail of exercise-induced chemicals being released into my system. I was experiencing feelings of extreme wellbeing despite the exhaustion setting in. Even though I was soaked in sweat and my head was spinning, I felt as if I could do anything (p. 164).

Sport offers a number of possibilities to thus empower the individual, especially those who have negative well-being in this regard. For example, the elder, disempowered adult, who may have lost a sense of well-being through retirement, may find a sense of achievement through participation, such as the elder athlete who joins a veterans running club, negotiating the inverse relationship between the ageing process and self-efficacy thus increasing the sense of 'I can', or the labelled long term unemployed who may lack structure or targets, those who may feel that there is no 'more' to one’s identity, and who may lack meaningful possibilities otherwise. More specifically, numerous studies exploring the lived experience of women have identified the potential of sport in providing a sense of physical vitality, and a belief in the body’s potential and ability (Yarnal, Hutchinson, \& Chow, 2006; Velija, Mierzwinski, \& Fortune, 2012; Aaltonen, 2013). Experiences 
grounded in identity mobility may be empowering as they demonstrate an increased confidence in one's own abilities to take on challenges. This has particular utility in terms of women's embedded experience as women generally face a more negative perception of their own physical abilities (Young, 1980; Young, 1990; Coakley, 2007).

Intertwining the two concepts leads us to the idea of Identity Dwelling-Mobility, which relates to the importance of having both an acceptance of one's present identity, but also a positive orientation towards future identities, for example, enjoying the sense of pride at being a runner, but with the desire to achieve more, even with the threat of pain or injury (Shipway \& Jones, 2007), thus merging the comfort with one's sporting identity, with future possibilities and opportunities. The very nature of sport, and its association with pathways of progression and performance makes it a particularly appropriate vehicle for Identity Dwelling-Mobility, with its entwined characteristics of present and future identities.

\section{Conclusion}

The proceeding discussion highlights the multiplicity of the dimensions of well-being, and offers examples of the different paths to well-being provided by sport. Taking a phenomenological approach to exploring wellbeing experiences through sport allows for individual exploration of the multiple life-world dimensions. Such an exploration provides ways of describing wellbeing experiences within a sports context that are more complex than those offered by more traditional approaches to study in this area. Our work provides a conceptual framework for future qualitative research into sport and wellbeing that may ultimately lead to more meaningful exploration of human experience grounded in the words of the experiencer. Furthermore, the adoption of a more qualitative phenomenological approach allows us to capture the range of wellbeing experiences that are possible through sport, and identify the deepest and most authentic wellbeing experiences that 
are possible within this context. Finally, a more in-depth phenomenological approach allows us to consider what aspects of lived experience may make wellbeing a possibility within a sports context in order to promote wellbeing moving forward. Ultimately, there are many benefits of the exploration of wellbeing experiences through the multiple life world dimensions within numerous disciplines and contexts.

Whilst the different experiential domains are clearly entwined, the above application specifically focuses on outlining examples of kinds of well-being which are facilitated when a single domain is emphasised. This approach reflects the earlier work of Galvin and Todres (2011) who presented each of the forms of well-being within individual domains to provide a clear typology of DwellingMobility theory. However, it is important to note that the implicated nature of each life world domain ensures that experiential possibilities for well-being may emphasise multiple domains simultaneously. Likewise, within and between these domains, Dwelling and Mobility may be experienced both together and independently, forging a multiplicity of diverse kinds of well-being. It may also be contended that some experiences may create a path for experiential well-being which emphasise certain domains and not others. Based on this notion, we feel that sport provides a relatively unique context for exploring this theory as it is one of the few activities that can clearly facilitate each of the different kinds of well-being within the life world domains. Other examples of activities that offer multiple kinds of well-being may include travel, cultural experiences, and the arts which all provide a range of possibilities for experiential well-being. More specifically, there is a need to explore how these other activities may offer opportunities for wellbeing within a sporting context e.g. sports tourism/ travel, or arts and cultural experiences associated with sports events such as the Olympics. We recommend that future research should focus on the application of this theory in multiple, diverse contexts to explore its value further. 
We also believe that sport provides an exceptional context for demonstrating the utility of the theory because, as a practice, it allows beings to inhabit the world in multiple diverse ways, and provides an ideal setting for the creation of meaning, mastery, and beauty. The application of Dwelling-Mobility theory reflects the humanising potential of sport as a focal practice, and allows the possibilities for well-being offered by sport to be explored via the various life world dimensions. In taking this approach, we make a valuable contribution to the existing literature on sport and wellbeing, and provide additional depth by exploring how sport may promote well-being, as opposed to merely identifying the presence of a relationship. In doing so sport practitioners and policy makers may have a clearer idea of how to facilitate these positive experiences for individuals.

Although a human-centred approach to exploring the relationship between sport and well-being has great utility for policy and practice generally, it also provides explicit opportunities for focussing on the paths to well-being offered through sport for disadvantaged groups and individuals who may experience sport in different ways. Specifically there is a need to use phenomenologically driven qualitative methods to explore how sport can facilitate well-being experiences for groups of individuals who are more likely to suffer from negative well-being. It is also important to consider how different societal groups may experience sport differently, and the impact this might have on their ability to experience a positive relationship between sport participation and personal wellbeing. One concrete example would be research exploring the relationship between sport and wellbeing for women. In making this exploration into women’s lived experience research must combine both social (feminist theory) and phenomenological (lived experience) approaches in order to explore women’s experience in a way that honours their situated freedom, or simultaneous embedded nature and agency. Such research would allow researchers to illuminate pathways for wellbeing for women through sport. In addition to exploring women’s experiences, research adopting a life-world approach to exploring the relationship between sport and wellbeing could also focus on other social groups that may experience sport in a unique and embedded manner such as 
older adults, people with a physical or mental disability, the chronically ill, and people from minority racial groups.

\section{References}

Aaltonen, E. (2013). Punching like a girl: Embodied violence and resistance in the context of women's self-defense. Journal of International Women's Studies, 13 (2), 51-65.

Allen-Collinson, J. (2009). Sporting embodiment: sports studies and the (continuing) promise of phenomenology, Qualitative Research in Sport and Exercise, 1 (3), 279-296.

Bishop, D., Karageorghis, C., \& Loizou, G. (2007). A grounded theory of young tennis players use of music to manipulate emotional state. Journal of Sport \& Exercise Psychology, 29, 584-607.

Bengoechea, E., and Strean, W. (2007). On the interpersonal context of adolescents'sport motivation. Psychology of Sport and Exercise, 8, 195-217.

Biddle, S., and Mutrie, N. (2008). Psychology of physical activity: determinants, well-being and interventions ( $2^{\text {nd }}$ edn). London: Routledge.

Breivik, G. (2007). Skilful coping in everyday life and in sport: A critical examination of the views of Heidegger and Dreyfus. Journal of the Philosophy of Sport, 34 (2), 116-34.

Breivik, G. (2013). Zombie-like or superconscious? A phenomenological and conceptual analysis of consciousness in elite sport. Journal of the Philosophy of Sport, 40 (1), 85-106. 
Bullough, S. (2012). A new look at the latent demand for sport and its potential to deliver a positive legacy for London 2012. International Journal of Sport Policy and Politics, 4 (1), 39-54.

Coakley, J. (2007). Sports in society: Issues and controversies ( $9^{\text {th }}$ edn). Boston: McGraw Hill.

Costa, C., and Chalip, L. (2005). Adventure sport tourism in rural revitalization - an ethnographic evaluation. European Sport Management Quarterly, 5 (3), 257-279.

Council of Europe (1993). European Sports Charter, Brussels: Council of Europe.

Csikszentmihalyi, M., 1990. Flow: the psychology of optimal experience. New York: Harper and Row.

Csikszentmihalyi, M. (1997). Finding flow: the psychology of engagement with everyday life. New York: Basic Books.

Dahlberg, K., Todres, L., and Galvin, K. (2009). Life world-led healthcare is more than patient-led care: an existential view of well-being. Medicine, Health Care and Philosophy, 12, 265-271.

Dale, G. (1996). Existential phenomenology: Emphasizing the experience of the athlete in sport psychology research. The Sport Psychologist, 10 (4), 307-21.

Daskalaki, M., Stara, A., and Imas, M. (2008). The ‘parkour organisation’: inhabitation of corporate spaces. Culture and Organization, 14 (1), 49-64. 
Department Of Health (2011). Start active, stay active: a report on physical activity from the four home countries. Chief Medical Officers. London: Department of Health.

Dolan, P., Peasgood, T., and White, M. (2008). Do we really know what makes us happy? A review of the economic literature on the factors associated with subjective well-being. Journal of Economic Psychology, 29 (1), 94-122.

Dreyfus, H., and Dreyfus, S. (1986). Mind over machine: the power of human intuition and expertise in the Era of Computer. New York: The Free Press.

Eime, R., Young, J., Harvey, J., Charity, M., and Payne, W (in press). A Systematic review of the psychological and social benefits of participation in sport for children and adolescents; informing development of a conceptual model through sport. International Journal of Behavioural Nutrition and Physical Activity, 10.

Galvin, K., and Todres, L. (2011). Kinds of well-being: A conceptual framework that provides direction for caring. International Journal of Qualitative Studies of Health and Well-being, 6 (4), doi: 10.3402/qhw.v6i4.10362.

Gould, D., and Carson, S. (2008). Life skills development through sport: current status and future directions. International Review of Sport and Exercise Psychology, 1(1), 58-78.

Heidegger, M. (1959). Discourse on thinking. New York: Harper Collins

Heidegger, M. (1962). Being and time. London: SCM Press. 
Heidegger, M. (1966). Conversation on a country path about thinking. In: M. Heidegger, Discourse on thinking. Trans. John M. Anderson and E. Hans Freund. New York: Harper and Row

Heidegger, M. (1975). Poetry, language and thought. New York: Harper \& Row.

Hockey, J., and Allen Collinson, J. (2007). Grasping the phenomenology of sporting bodies. International Review for the Sociology of Sport, 42 (2), 115-131.

Hoffmann, P. (1997). The endorphin hypothesis. In: W. Morgan (editor) Physical activity and mental health. Washington: Taylor \& Francis, 213-232.

Kavetsos, G., and Szymanski, S. (2008). National well-being and international sports events. Working Paper Series, Paper No. 08-04, North American Association of Sports Economists.

Lehnert, K., Sudeck, G., and Conzelmann, A. (2012). Subjective well-being and exercise in the second half of life: A critical review of theoretical approaches. European Review of Aging and Physical Activity. 9 (2), 1-16.

Lloyd, K., and Little, D. (2010). Self-determination theory as a framework for understanding women's psychological well-being outcomes from leisure-time physical activity. Leisure Sciences, 32 (4), 369-385.

Lundqvist. C. (2011). Well-being in competitive sports - the feel-good factor? A review of conceptual considerations of well-being. International Review of Sport and Exercise Psychology, 4 (2), 109-127. 
McCarville, R., (2007). From a fall in the mall to a run in the sun: One journey to ironman triathlon. Leisure Sciences, 29(2), 159-173.

McMahan, E., and Estes, D. (2011). Hedonic versus eudemonic conceptions of well-being: Evidence of differential associations with experienced well-being. Social Indicators Research, 103, 93-108.

Markser, V. ( 2011). Sport psychiatry and psychotherapy: Mental strains and disorders in professional sports. Challenge and answer to societal changes. European Archives of Psychiatry and Clinical Neuroscience, 261 (Supplement 2), S182-S18.

Merleau-Ponty, M. (1968/1948). The visible and the invisible (trans: Lingis, A.). Evanston, IL: Northwestern University Press.

Merleau-Ponty, M. (1987/1960). Signs (trans: McCleary, R.). Evanston, IL: North Western University Press.

Merleau-Ponty, M. (1995/1945). Phenomenology of perception (trans: Smith, C.). London: Routledge.Mitchell, R., 1983. Mountain experience: The psychology and sociology of adventure. Chicago: University of Chicago Press.

Ntoumanis, N., Thøgersen-Ntoumansi, C., and Taylor, I. (2012). A longitudinal examination of coach and peer motivational climates in youth sport: Implications for moral attitudes, wellbeing, and behavioral investment. Developmental Psychology, 48 (1), 213-223. 
Omalu, B., Hamilton, R., Kamboh, M., DeKosky, S. and Bailes, J. (2010). Chronic traumatic encephalopathy (CTE) in a National Football League Player: Case report and emerging medicolegal practice questions. Journal of Forensic Nursing, 6 (1): 40-46.

Rejeski, W., and Mihalko, S., (2001). Physical activity and quality of life in older adults. Journal of Gerontology Series A: Biological Sciences and Medical Sciences, 56 (2), 23-35.

Ryan, R., and Deci, E. (2001). To be happy or to be self-fulfilled: A review of research on hedonic and eudaimonic well-being. In: S. Fiske (Editor.), Annual Review of Psychology 52,. Palo Alto, CA: Annual Reviews Inc. 141-166.

Self, A., and Randall. C. (2013). Measuring national well-being - Review of domains and measures. London: Office of National Statistics.

Shipway, R., and Jones, I. (2007). Running away from home: Understanding visitor experiences and behaviour at sport tourism events. International Journal of Tourism Research, 9 (5), 373383

Shipway, R., and Jones, I. (2008). The great suburban Everest: An insiders’ perspective on experiences at the 2007 Flora London Marathon. Journal of Sport \& Tourism, 13 (1), 61-77.

Smith, S., and Lloyd, R. (2006). Promoting vitality in health and physical education. Qualitative Health Research: An International Interdisciplinary Journal, 16 (2), 245-267.

Teixeira Reis, A. (2011). Epistemology of health, quality of life, social connectedness and the contribution of sports for subjective well-being. Sport Science Review, 3-4, 25-56. 
Theberge, N. (2008). “Just a normal bad part of what I do”: Elite athletes’ accounts of the relationship between health and sport. Sociology of Sport Journal, 25 (2), 206-222.

Todres, L., and Galvin, K. (2010). “Dwelling-mobility”: an existential theory of well-being. International Journal of Qualitative Studies on Health and Well-being 5 (3), 1-6.

Todres, L., Galvin. K., and Dahlberg, K. (2007). Life world-led healthcare: revisiting a humanising philosophy that integrates emerging trends. Medicine, Health Care and Philosophy, 10, 53-63.

Velija, P., Mierzwinski, M., and Fortune, L. (2012). "'It made me feel powerful’: Women’s gendered embodiment and physical empowerment in the martial arts." Leisure Studies, 32 (5), $1-18$.

Verkooijen, K., van Hove, P., and Dik, G., (2012). Athletic identity and well-being among young talented athletes who live at a Dutch elite sport center. Journal of Applied Sport Psychology, 24 (1), 106-113.

World Health Organisation. (2012). Basic documents (39th edn). Geneva: WHO.

Yarnal, C., Hutchinson, S., and Chow, H. (2006). "“I could probably run a marathon right now”: Embodiment, space, and young women's leisure experience." Leisure Sciences, 28 (2), 133161.

Young, I. (1980). "Throwing like a girl: A phenomenology of feminine body comportment motility and spatiality." Human Studies, 3 (1), 137-156. 
Young, I. (1990). Throwing like a girl and other essays in feminist philosophy and social theory, Indiana University Press: Bloomington. 